\title{
A justiça de Kira: representações da justiça no anime Death Note a partir da teoria da audiovisão
}

\section{KIRA'S JUSTICE: REPRESENTATIONS OF JUSTICE IN THE ANIME DEATH NOTE ANIME FROM AUDIOVISION'S THEORY}

Amanda Muniz Oliveira ${ }^{1}$ Rodolpho Alexandre Santos Melo Bastos ${ }^{2}$ 


\section{Resumo}

As animações japonesas, também conhecidas como animes, são populares produções audiovisuais no ocidente, especialmente no Brasil. Criadas para públicos de diferentes idades e abordando temáticas diversas, os animes tornamse interessantes fontes de pesquisa para se compreender discursos e representações veiculadas socialmente. Neste sentido, o presente artigo propõe analisar de que forma um ideal de justiça é representado no anime Death Note (a partir do personagem Light Yagami) que possui um envolvente enredo relativo a questões como assassinatos e vingança. Assim, visto que a junção entre imagem e sons é crucial para os efeitos de impacto na audiência do anime, utilizaremos a teoria da audiovisão proposta por Michel Chion, no intuito de demonstrar como tais elementos geram significados conjuntamente, de forma a complementar sentidos e direcionar a percepção dos espectadores.

Palavras-chave: audiovisão, Death Note, justiça.

\section{Abstract}

The Japanese animations, also known as anime, are popular audiovisual productions in the West, especially in Brazil. Created for public of different ages and addressing various topics, animes become interesting research sources to understand discourses and representations conveyed socially. In this sense, this article aims to analyze how an ideal of justice is represented in the Death Note anime (from the character Light Yagami) that has an engaging plot about questions as murder and revenge. Thus, since the junction between image and sound is crucial for the purposes of impact on the anime audience, we will use the theory of audiovision proposed by Michel Chion, in order to demonstrate how these elements generate meanings together, in order to supplementing senses and directing the perception of the spectators.

Keywords: audiovision, Death Note, justice.

ISSN: 2175-2346

\footnotetext{
${ }_{1}^{1}$ Doutoranda em Direito pelo Programa de Pós-Graduação em Direito da Universidade Federal de Santa Catarina - PPGD/UFSC. Mestra em Direito pelo PPGD/ UFSC. Bacharela em Direito pelas Faculdades Santo Agostinho de Montes Claros - MG - FADISA. Brasil amandai040@gmail.com

${ }^{2}$ Doutorando em História pelo Programa de Pós-Graduação em História da Universidade Federal de Santa Catarina - PPGH/UFSC. Mestre em História pelo Programa de Pós-Graduação em História da Universidade Estadual de Montes Claros - UNIMONTES. Brasil rodoxbastos@gmail.com.
} 


\section{Introdução}

Os textos midiáticos, inclusive as animações, não são neutros. Tais obras dialogam diretamente com o período no qual foram produzidas, de forma que absorvem e representam debates, angústias e preocupações de sua época, seja de forma a reforçar o estabelecido ou contestar o que está vigente.

Douglas Kellner (2001) chama atenção para a cultura da mídia, que, constituída por meios audiovisuais (música, cinema, animações, televisão, telejornalismo, etc.) e também por meios escritos (jornais, revistas e histórias em quadrinhos, mangás, etc.), é responsável por construir opiniões das mais diversas, sendo capaz, ainda de fornecer subsídios para que o indivíduo crie sua própria identidade, ofertando assim modelos do que é desejável e do que não é; do que é ser homem e do que é ser mulher; do que é bom ou mau, etc. Além disso, atenta para o fato de que a mídia pode ainda auxiliar na desconstrução de ideologias e preconceitos.

Desta forma, entendemos que dentre estas representações diversas, temas com gênero, questões raciais, política e economia aparecem de forma latente, mas não exclusiva. Se há uma relação entre sociedade e textos midiáticos, é possível afirmar que temas como poder e justiça também são ali abordados.

Dito isso, é preciso chamar atenção para o que se entende como representações. Para Denise Jodelet (2002), tal conceito refere-se a forma de interpretar a realidade social, a manifestação da atividade mental desenvolvida pelos indivíduos e seus grupos, uma vez que fornece sentido à realidade cotidiana, fixando valores, normas, condutas, hábitos, etc. Para a referida autora, as representações sociais circulam nos discursos, palavras, mensagens e imagens midiáticas e são cristalizadas nas condutas sociais.

Em suma, tentaremos demonstrar de que forma uma noção de justiça aparece em uma animação japonesa, Death Note. A escolha de um anime, em detrimento de animações ocidentais, se dá pela forma como determinados assuntos são abordados nas produções orientais; diferentemente do que ocorre aqui, os animes não são produções exclusivamente infantis. Assim, temas complexos e relevantes podem ser abordados de uma maneira mais aprofundada, levantando importantes questões a serem pensadas. Neste sentido, o título Death Note se destaca por abordar de forma envolvente questões como justiça, poder, ética, moralidade e assassinato. O personagem principal passa a matar bandidos com o objetivo de conseguir criar um mundo melhor, mas logo é perseguido pela polícia e acusado de ser tão criminoso quanto suas vítimas, de forma que indagamos: o que tal personagem entende por justiça?

Além disso, optou-se pelo anime Death Note e não por seu mangá ${ }^{1}$ em razão da articulação entre som, imagem e palavra, capazes de gerar novos sentidos, novas impressões e novas possibilidades de interpretação ao que antes era apenas lido. A trilha sonora do anime, bem como as músicas de abertura, tom de voz dos personagens e ruídos secundários são minuciosamente sincronizados com os elementos visuais, intensificando a seriedade e o suspense da trama.

O trabalho está estruturado da seguinte forma: inicialmente, faremos uma

1 Quadrinhos japoneses. Death Note foi lançado inicialmente neste formato e só depois tornou-se anime. 
contextualização dos animes como produtos midiáticos no ocidente, bem como apresentaremos alguns detalhes concernentes à obra Death Note. Em seguida, explicaremos a metodologia de análise utilizada, qual seja, a teoria da Audiovisão, proposta por Michel Chion, que se debruça sobre a relação entre som e imagem. Por fim, será apresentada nossa proposta de análise e o conceito de justiça presente no anime, a partir da visão do personagem Light Yagami.

\section{O Anime}

Segundo Schmaltz Neto (2013), a palavra anime, no Japão, é utilizada para designar todo e qualquer desenho animado, enquanto no ocidente convencionou-se a utilizá-la unicamente para as produções japonesas. Todavia, animes e desenhos animados possuem diferenças diversas, dentre as quais Schmaltz Neto (2013) aponta a história sequencial, que nos obriga a assistir os episódios em ordem cronológica, a certeza de um final definitivo para a narrativa e os traços suaves, que destacam características dos personagens. Além disso, é importante destacar que o público alvo dos animes é variável, diferentemente do que ocorre no ocidente, onde animações, em geral, visam especificamente o público infanto-juvenil. Schmaltz Neto (2013, p.62) explica essa diferenciação:

\footnotetext{
O desenho animado para o Homem do Ocidente ainda carrega resquícios da Guerra Fria em 1950 com a perseguição e controle de estúdios decorrentes do depoimento de Walt Disney, que compareceu ao Comitê de Atividades Antiamericanas como uma "testemunha amigável" para afirmar que desenhos comunistas estavam sendo feitos por norte-americanos. Como as produções a partir daí eram cada vez mais insossas, convencionou-se que qualquer narrativa cinematográfica que não utiliza atores reais é restrita ao público infantil (Sato 2007:32). Para o Japão, ao contrário, o animê é Arte, e por isso está destinado a todos os públicos. Os escritores o fazem para donas de casa, empresários, adolescentes e mesmo pessoas com fetiches sexuais.
}

Apesar do anime ter se originado no início do séc. $\mathrm{XX}$, é apenas a partir do ano de 1968, conforme Schmaltz Neto (2013) que chegará ao Brasil. Todavia, somente nos anos 90 e 2000 que as produções caem em definitivo no gosto nacional, graças à TV Manchete e a Rede Bandeirantes, que incluíram diversos animes de sucesso em suas programações, como Cavaleiros do Zodíaco, Shurato, El Hazard e Dragon Ball Z.

Entretanto, embora o anime Death Note tenha sido lançado em 2006 no Japão, só será exibido no Brasil em 2009, pelo canal pago Animax, não sendo assim tão popular como outros títulos japoneses. Acreditamos que tal fato pode ser explicado pela própria densidade da narrativa, que recebeu classificação etária de 16 anos. Mesmo que o anime tenha um público específico no cenário nacional, ainda é lugar comum identificar animações com audiência infanto-juvenil, de forma que a TV aberta teria de realizar cortes e censuras para adaptar o enredo a um público mais jovem, o que seria dispendioso e talvez não muito lucrativo, visto que se trata de um anime curto (possui apenas 37 episódios).

Ainda assim, acreditamos que a internet tenha ajudado na disseminação da obra, visto que diversos sites disponibilizam o anime na íntegra, em sua versão dublada e 
legendada, e no primeiro semestre de 2016 o site de streaming Netflix também a disponibilizou em seu catálogo. Ademais, não é muito difícil encontrar pela internet fóruns e fã-clubes relativos ao anime, bem como produtos comercializáveis (camisas, cadernos, action figures, etc.) e mesmo pessoas caracterizadas como os personagens, em eventos específicos de cultura pop.

No cenário mundial, Schmaltz Neto (2013, p. 81) oferece um panorama geral:

[O sucesso de Death Note] é relembrado constantemente, figurando na lista de melhores animês do século, seja pelo grande feito em ser uma narrativa essencialmente firmada no gênero suspense em meio a uma revista cuja tradição sempre rodeou histórias de lutas e torneios, seja pela polêmica causada em algumas regiões asiáticas como a Tailândia e seu banimento da China; apesar de encerrada, rendeu três longas metragens no formato live-action produzidos pela Warner Bros nipônica, três jogos de investigação pela plataforma Nintendo DS,e e a compra de direitos autorais pela Warner Bros estadunidense para produção de um longa com atores reais. Portugal o conheceu apenas em fevereiro de 2012 pela editora Devir.

Baseado no mangá homônimo, escrito por Tsugumi Ohba e desenhado por Takeshi Obata, o anime mistura elementos sobrenaturais e questões morais e éticas, criando um enredo atrativo e permeado de suspense. Tudo começa quando Light Yagami, considerado o jovem mais inteligente do Japão, entediado com sua rotina, encontra por acaso um estranho caderno. Nomeado de Death Note (caderno da morte, em inglês), suas primeiras páginas afirmam que se trata de um caderno com um poder especial: o de matar as pessoas cujos nomes forem nele escritos. Existem diversas regras sobre os usos desses poderes, como por exemplo ter o rosto da pessoa em mente, especificar a causa da morte em até 40 segundos sob pena da pessoa escolhida falecer de ataque cardíaco, dentre outras. Light, um aluno racional, mostra-se cético até que decide testar o caderno e descobre que seu poder é real. Posteriormente o estudante descobre que o objeto pertence a um shinigami, um Deus da Morte, que, também entediado com seu mundo, resolve lançar o caderno a terra para ver o que aconteceria.

Montado o cenário, a trama introduz diversos personagens e dilemas diferentes. Light, ciente do poder que tem em mãos, resolve utilizar o caderno para assassinar todos aqueles que praticaram algum tipo de crime, no intuito de fazer do mundo um lugar melhor. As coisas se complicam, porém, quando a polícia desconfia de um assassino por trás das mortes misteriosas e passa a caçar a misteriosa figura, vez que Light mantem-se em anonimato. $O$ assassino passa a ser chamado de Kira ${ }^{2}$ e divide a opinião pública: alguns o consideram um Deus por punir os malfeitores; outros, um demônio por brincar com vidas humanas. O maior detetive do mundo é contratado para resolver o caso, e assim inicia-se uma intrigante caçada, na qual Light não hesitará em manipular e até assassinar as pessoas que cruzem seu caminho. O jovem passa a ser corrompido pelo poder e sangue inocente é derramado para que ele prossiga com seu ideal de justiça.

Os traços, as cores, os efeitos sonoros, as entonações das vozes e todos os demais elementos audiovisuais são empregados de forma a aumentar e a destacar a tensão que permeia todo o anime. Desta forma, pretendemos demonstrar como as

2 Referência à palavra killer, assassino em inglês. 
articulações entre som e imagem, especificamente, potencializam e mesmo criam determinados efeitos e significados, impactando ao público que assiste a narrativa. Para tanto, utilizaremos a teoria da audiovisão, de Michel Chion, a ser abordada no seguinte tópico.

\section{Audiovisão: aspectos gerais}

Para Chion (1993), embora as obras audiovisuais apresentem o elemento imagem de forma mais notória, não se pode esquecer do elemento som. Para o autor (p.10), “las películas, la televisión y los medios audiovisuales en general no se dirigen sólo a la vista. En su espectador -su «audio-espectador»- suscitan una actitud perceptiva específica que, en esta obra, proponemos llamar la audiovisión."

Embora sejam um todo completo, Chion (1993) afirma que ainda se insiste ou em ignorar completamente o elemento som - dizendo, ver um filme, por exemplo - ou em compreender os dois elementos como duas coisas isoladas. A audiovisão, assim, vai mais a fundo: pretende demonstrar que os significados e as percepções do espectador estão intimamente relacionados aos sons que aparecem nas imagens audiovisuais. Segundo o autor (p. 10), isto ocorre porque "una percepción influye en la otra y la transforma: no se «ve» lo mismo cuando se oye; No sé «oye» lo mismo cuando se ve."

Importante destacar que ao falar em som, Chion (1993) refere-se à toda banda sonora componente do vídeo; a música fundo não é sua única preocupação. Ruídos secundários, efeitos sonoros e as vozes também precisam ser objeto de análise, pois auxiliam no sentido da obra. A preocupação do autor portanto, é demonstrar como os diversos sons causam impacto nas significações do vídeo, e como o contexto do vídeo também age na percepção dos sons.

A teoria de Chion (1993) pode ser aplicada a diferentes obras audiovisuais, como o cinema, videoclipes, esportes e mesmo desenhos. O autor desenvolve diversos conceitos e estratégias para se analisar a relação entre som e imagem a partir de uma obra audiovisual. Alguns conceitos chaves para a análise são: a) Valores adicionados: compreendido por Chion (1993, p.07) como:

el valor expresivo e informativo con el que un sonido enriquece una imagen dada, hasta hacer creer, en la impresión inmediata que de ella se tiene o el recuerdo que de ella se conserva, que esta información o esta expresión se desprende de modo «natural» de lo que se ve, y está ya contenida en la sola imagen.

b) Síncrese: para Chion (1993, p. 56) trata-se da "soldadura irresistible y espontánea que se produce entre un fenómeno sonoro y un fenómeno visual momentáneo cuando éstos coinciden en un mismo momento, independientemente de toda lógica racional". É basicamente a forma como a imagem evoca um som e este evoca a imagem; uma associação realizada imediatamente pelo espectador; c) Consistência da banda sonora: Segundo Chion (1993, p. 145): "Puede llamarse consistencia de la banda sonora a la manera en que los diferentes elementos sonoros -voces, música, ruidos- están más o menos incluidos en una misma pasta global, una textura o, por el contrario, oídos cada uno por separado de manera muy legible". Para o autor 
(1993, p.145) as funções da consistência seriam:

- de un equilibrio general de los niveles, en los que éstos se combaten y luchan por acceder a la inteligibilidad,

- de la mayor o menor presencia de una reverberación, que puede hacer borrosos los contornos sonoros y fabricar una especie de sustancia blanda y unificadora, que enlace los sonidos entre sí.

- de los fenómenos de máscara, ligados a la coexistencia de diferentes sonidos en los mismos registros de frecuencias.

Conforme Chion (1993, p. 147), as perguntas "-¿Qué veo de lo que oigo? - ¿Qué oigo de lo que veo?" seriam cruciais para compreender essas relações; d) Sons no vazio: quando a imagem está presente, mas o som, ausente; e) Imagens negativas: quando o som está presente, mas a imagem, ausente.

Ainda a partir do videoclipe escolhido, realizaremos no tópico seguinte as estratégias: 1) Procedimento de observação do qual fazem parte; a)Método dos ocultadores, que consiste em assistir o vídeo a ser estudado várias vezes, sem áudio e sem imagens, para depois comparar tais percepções com aquelas que se obtém assistindo o vídeo integrado (com som e com imagem); b)Matrimônio da força, que seria exibir as imagens, sem áudio, sobrepostas por diferentes sons; seria este procedimento o responsável por expor os valores adicionados e as síncreses.

A segunda estratégia a ser aplicada será: 2) Esboço de um questionário modelo. Chion (1993) recomenda realizar uma espécie de questionário, de forma a identificar as relações entre som e imagem. Para o autor, (p.145) perguntas como "¿hay palabras? ¿Música? ¿Ruidos? ¿Cuál es dominante y se destaca? ¿En qué lugar?" podem auxiliar na: a)Busca de dominâncias e descrição de conjuntos: questionando-se os tipos de som que aparecem no vídeo, como vozes, ruídos, ou músicas, é possível caracterizar o aspecto geral do som e a consistência de toda a banda sonora.; b) Localização de pontos de sincronização importante, providos de sentido e efeito; c)Comparação, ou seja, a forma como som e imagem interagem para criar ou reforçar novos sentidos e representações. Isso auxilia na percepção do tempo, da distância, da matéria e mesmo da definição. Nas palavras de Chion (1993, p.146)

Por ejemplo, en el planos de la velocidad: el sonido y la imagen pueden tener velocidades contrastadas, y esta diferencia crear una sutil complementariedad de ritmo. Lo mismo sobre la cuestión de la materia y de la definición: un sonido duro y cargado de detalles puede combinarse con una imagen parcialmente difuminada e imprecisa, o a la inversa, lo que produce siempre un efecto interesante. Naturalmente, esta comparación no puede hacerse sino observando los dos elementos, sonoro y visual, de modo disociado, por el método de los ocultadores. Por otra parte, es interesante ver cómo cada elemento asume su parte figurativa y narrativa y cómo ambos se completan, se contradicen o son redundantes en este plano. Por ejemplo, en la cuestión de la distancia y de las escalas, estando el personaje lejos en la imagen y su voz próxima, o al revés. La imagen puede estar poblada de detalles narrativos y el sonido ser parco en sonorizaciones, o a la inversa: una imagen vacía y un sonido copioso. La combinación contrastada de los dos tiene, generalmente, un poder evocador y expresivo más fuerte, pero, de nuevo, no se percibirá conscientemente como tal.

Importante mencionar ainda a possibilidade de se analisar a relação entre som e 
imagem a partir da comparação técnica (a forma como os movimento de câmera se integram aos sons). Determinados estes conceitos e estratégias, partimos para nossa análise.

\section{A justiça em Death Note a partir da Audiovisão}

Para realizar nossa análise, selecionamos as cenas nas quais a ideia de justiça de Light Yagami, ou Kira, é justificada e/ou criticada. Partindo deste filtro, encontramos cenas nos episódios 01, 02, 13 e 30.

No episódio 01, Rebirth, após comprovar a veracidade do Death Note, nos é mostrado o momento em que Light realiza suas primeiras mortes, assassinando dois criminosos. O cenário é sombrio, o estudante caminha transtornado pela chuva, questionando se suas ações foram corretas, afinal, aquelas eram vidas humanas. Como valores adicionados e síncrese, tem-se o som da chuva, que é sobreposto pela voz de Light, em tom de preocupação. Quando a câmera foca no estudante, o som da chuva some, embora sua imagem ainda seja mostrada: trata-se de um som no vazio, utilizado para enfatizar os dilemas de Light. A câmera foca-se no personagem, utilizando closes. Há ainda uma música de tensão ao fundo, que transmite ao expectador o medo, a apreensão e as dúvidas do personagem. Trata-se da faixa Low of Solipisism, composta para o anime por Yoshihisa Hirano e Hideki Taniuchi.

Esta cena é crucial para o desenrolar do enredo, pois é neste momento em que o personagem Light teoriza internamente sobre o ideal de justiça. Mesmo que tal ideal não seja um consenso, instintivamente o personagem compreende ser errado tirar vidas humanas. Todavia, conforme Yamamoto (2015) o sistema jurídico japonês ainda aplica a pena de morte como forma de punição, de forma que apresenta-se aqui uma dicotomia: é moralmente questionável que um cidadão comum cometa homicídio, mas o Estado por meio de suas instituições jurídicas detém essa prerrogativa. Voltaremos a este ponto em outros momentos.

Retomando a cena anteriormente descrita, logo Light se convence de que o mundo está podre e precisa ser purificado, cabendo a ele este papel. A medida em que ele vai procurando justificativas para suas ações, a música ainda tensa se acelera; a câmera destaca que os olhos castanhos do personagem se tornam vermelhos, e as imagens, antes sombrias, passam a receber feixes de luz. O personagem diz:

Eu... Eu matei... Eu matei duas pessoas. É a vida... Não pode ser tão fácil. Quem sou eu para julgar os outros? Não, espere. Não é nisso que tenho pensado? $\mathrm{O}$ mundo está uma podridão. Todos que são podres merecem morrer. Alguém deve fazer isso. Mesmo que custe sua vida e sua alma. Este mundo precisa ser limpo! Supondo que outra pessoa pegasse o caderno, ela seria capaz de extinguir as pessoas inúteis do mundo? Claro que não! Mas eu posso. Eu posso fazer isso. Não, eu sou o único que pode fazê-lo! Vou fazer isso usando o Death Note, vou mudar o mundo!

A chuva permanece como um som vazio, até que finalmente desaparece: tratase de um interessante ponto de sincronização, pois a imagem desaparece ao mesmo tempo em que as dúvidas do personagem se evanescem. Na sequência, um coral 
começa a entoar um canto forte, que diz "Kira, deus vici canti / Kira, deus!"3. A música permanece e nos é mostrado que Light passa a escrever uma grande quantidade de nomes no caderno da morte, enquanto diversos criminosos morrem. Os versos estão perfeitamente sincronizados com o enredo, pois trata-se do momento de criação do vilão Kira. As imagens e os sons articulados demonstram, em um primeiro momento, a dúvida e a hesitação, afinal, como se questiona Light, "quem sou eu para julgar os outros?". Percebe-se aqui indícios de uma justiça baseada no senso comum; não se pode defini-la explicitamente, mas algumas ações parecem contrariá-la, como o ato de retirar a vida de outros humanos considerados inúteis.

Porém, à medida em que Light reflete sobre o mundo em que vive, se convence de que este ambiente está podre e precisa ser limpo. O personagem idealiza a necessidade de um herói, que livre a sociedade de seres malignos, evocando assim um pensamento puramente maniqueísta. Por se considerar o único com o poder e a coragem necessária para realizar essa limpeza, ele se arroga paladino da justiça, ou melhor, do que ele acredita ser a justiça: eliminar os criminosos e preservar os cidadãos de bem, aqueles que não cometem sanções criminais. Light se coloca como um ser superior, acima inclusive de divindades ou dogmas religiosos, por não temer perder sua alma, e do Estado, já que pode-se inferir sua insatisfação com o tratamento jurídico japonês que, mesmo adotando a pena de morte, não é capaz de realizar uma limpeza social.

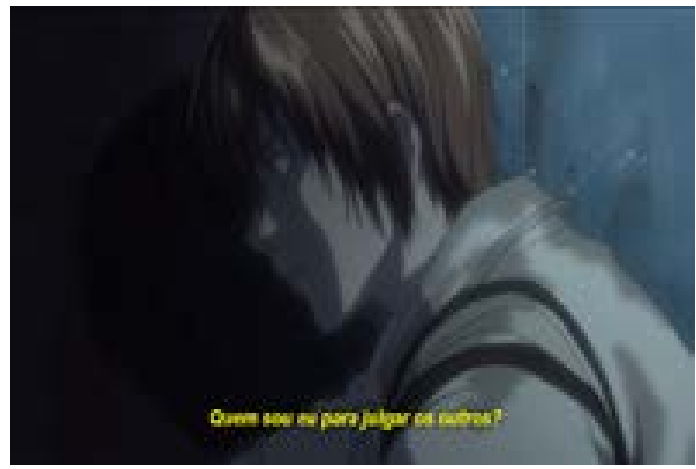

Figura 01: Light apreensivo.

Fonte: Death Note (Desu nôto). Japón: Mad House / D.N. Dream Partners / NTV / Shueisa Nideo Audio Project. 2006.

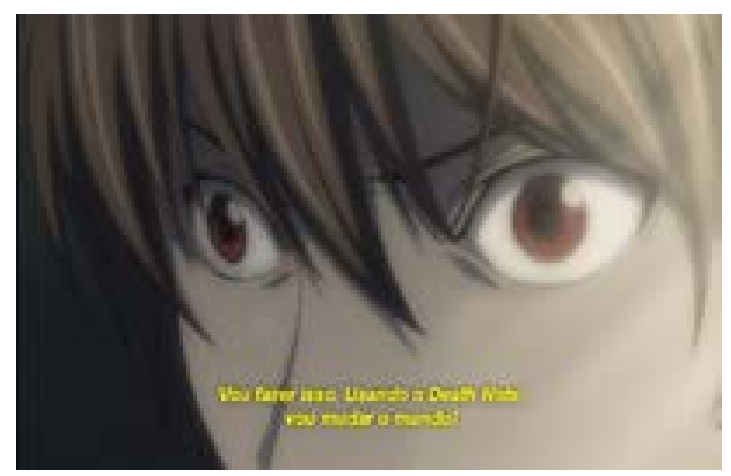

Figura 02: Light decidido a matar.

Fonte: Death Note (Desu nôto). Japón: Mad House / D.N. Dream Partners / NTV / Shueisa Nideo Audio Project. 2006.

3 Tradução: "Kira, deus, rua, canção / Kira, deus!". Disponível em: < https://www.letras.mus.br/death-note/low-of-solipsism/traducao.html>. Acesso em 08 mai. 2016. 
Desta forma, é apresentado ao espectador a transformação do personagem e a justificativa para suas ações. Apesar de relutar, Light conclui que é seu papel transformar o mundo em lugar melhor, eliminando os criminosos que atormentam a paz da humanidade. Neste mesmo episódio, porém, nos é revelado que o estudante apenas quer mudar o mundo pois estava entediado: não há uma motivação verdadeiramente nobre ou moral. A música sombria reforça este sentido sendo o som predominante da cena, assim como a ausência de cores vibrantes, já que a epifania de Light, apesar de acompanhada por alguns feixes de luz, continua predominantemente obscura, conforme figuras 01 e 02.

No episódio 02, Confrontation, Light descobre que as mortes de criminosos estão sendo atribuídos a um indivíduo, Kira, cuja identidade é um mistério. Ocorre que Light repete o método de assassinato, apontando ataque cardíaco como a causa da morte de suas vítimas, padrão logo percebido pela polícia e pela população. Por meio da internet, diversas pessoas manifestam seu apoio aos assassinatos, o que deixa Light contente. Assim, ele passa a explicar a seu companheiro shinigami (deus da morte) Ryuuku, dono anterior do caderno, que os seres humanos consideram errado o ato de matar, mesmo que os mortos sejam criminosos. Todavia, isso é apenas uma resposta social, sendo que no íntimo todo indivíduo tem o desejo de eliminar bandidos.

São indícios que corroboram a ideia de justiça defendida por Light: mesmo que hajam acepções múltiplas para o que seja de fato justiça, há um certo consenso social de que cometer homicídio é algo equivocado. Não se pode assumir abertamente que a autotutela, ou seja, a resolução de conflitos por meios particulares, fora do âmbito estatal por meio das instituições jurídicas, seja uma opção justa ou correta, mesmo que internamente se pense nela como a melhor opção. Desta forma, é necessário poder e coragem para se recorrer à autotutela: Light detém ambos e por isso entende que pode agir conforme bem entender, longe de limitações como dilemas morais, religiosos ou mesmo jurídicos.

Na cena descrita, há um fundo musical que evoca a ideia de raciocínio lógico, como se para demonstrar que Light estivesse argumentando de forma completamente racional. Seu tom de voz é calmo, e se sobrepõe à canção de fundo. Algumas imagens do cotidiano social são mostradas, enquanto ele explica a necessidade de se seguir normas sociais ao shinigami; neste momento há presença de sons no vazio, pois o único som que se houve é a voz do estudante e a canção de fundo - sua argumentação é o cerne da cena.

É então que a Interpol, Organização Internacional de Polícia Criminal, exibe na televisão um pronunciamento feito pelo maior detetive da história, conhecido como $L$, reconhecendo a existência de Kira e condenando suas ações, chamando-o de serial killer. A voz de $L$ é firme e, quando fala inicialmente, é o único som da cena. Após revelar sua identidade, uma música de tensão inicia-se e a voz de Light é ouvida, indagando quem seria este indivíduo, com um tom de preocupação. Em seguida, a voz de Light se eleva e o personagem parece ligeiramente entusiasmado, ao se lembrar de que não pode ser preso sem que a polícia saiba das questões sobrenaturais que o circundam.

Ao ser chamado de criminoso, há uma pausa sonora e o foco é o rosto de Light, 
de forma a enfatizar o quanto ser classificado como bandido o ofende. Nota-se aqui que o seu conceito de justiça é extremamente particular: para ele, o fato de matar apenas bandidos não é algo injusto. A câmera dá um close em seus lábios, que formam um sorriso; de olhos arregalados e em um tom de voz alto, quase um grito, Light rapidamente mata o homem que via na televisão - provando que sua justificativa nobre de assassinar apenas bandidos poderia ser modificada a qualquer tempo. Neste sentido, pertinente observar que mesmo matando um inocente (pois até então $L$ fora apresentado como um policial), Light não entende estar cometendo um crime ou uma injustiça: há na verdade uma complementação a seu conceito. Justiça a partir de então seria assassinar criminosos, e também eliminar todos aqueles que cruzem seu caminho, independentemente de suas fichas criminais. É este conceito autoritário que irá guiar suas ações durante todo o enredo.

Reviravolta surpreendente ocorre quando uma voz na televisão afirma que o homem assassinado não era o verdadeiro $L$ : o detetive apenas havia se utilizado de um dublê para provar alguns pontos. A identidade de $L$ continua em segredo, o que faz com que ele esteja fora do alcance de Light, que precisa de um rosto e de um nome para matar. Para o detetive, Kira não passa de um assassino que merece ser levado à justiça estatal por acreditar estar acima da lei e condenado à pena de morte. $N a$ cena descrita, a imagem do verdadeiro $L$ é um simples $L$ preto em tela branca; sua voz é robótica, alterada por computadores para preservar sua identidade. Desta forma, $L$ apresenta-se quase como uma entidade. Assim que o verdadeiro detetive começa a falar, uma música de fundo que evoca raciocínio lógico recomeça, demonstrando que tudo fora parte de um plano cuidadosamente arquitetado. Quando as explicações de $L$ são finalizadas, Light se acalma e diz aceitar o desafio. A música Low of Solipisism é tocada novamente em sincronia com a fala do estudante, e a imagem foca-se na dualidade entre Light e $L$, cada uma firmando que apenas ele próprio é defensor da justiça, conforme figura 03. Ambos são apresentados com cores sombrias, e os olhos de Light estão novamente em vermelho, realçando seu desejo pela efetivação de sua justiça.

Vários questionamentos podem ser realizados aqui. O personagem $L$, que aparece como um antagonista de Light, também age a partir de uma pretensão assassina: deseja condená-lo à pena de morte, conforme o sistema jurídico japonês. A diferença entre as ações reside no fato de que um pretende agir de forma isolada e realizar a sua própria justiça ao matar quem ele mesmo julgar inconveniente; o outro, por sua vez, pretende agir dentro dos parâmetros legais, tirando uma vida a partir de uma licença institucional. No anime, a sociedade se assusta com as ações de Light, mas não questiona a atuação estatal, como se o Estado não pudesse cometer erros ao proferir seus próprios julgamentos. Esse apego à morte como forma de justiça é salientado pelos tons sombrios e pela tensão musical que embala a cena, como se ambos os personagens estivessem equivocados, mas nenhum soubesse disso. 


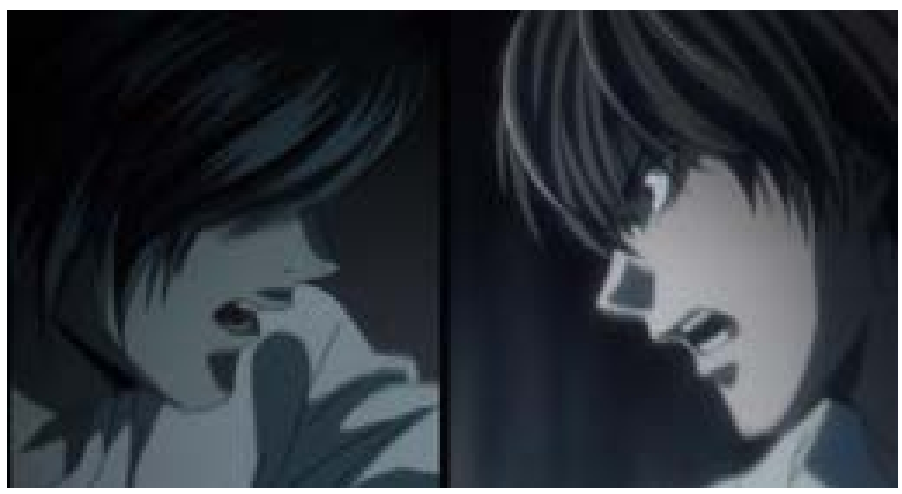

Figura 03: L versus Kira.

Fonte: Death Note (Desu nôto). Japón: Mad House / D.N. Dream Partners / NTV / Shueisa /Video Audio Project. 2006.

No episódio 13, Confession, a personagem Misa Amane, uma garota que adquire os mesmos poderes de Light, o encontra e revela sua admiração por Kira. Para a garota, a justiça de Kira é a única realmente eficaz, pois ela viu os pais serem assassinados e o criminoso sair impune. Depois de Kira iniciar sua atuação, o autor do crime também foi morto, trazendo à Misa a sensação de que a justiça havia sido feita. Desta forma, ao descobrir que Light e Kira são a mesma pessoa, ela se oferece como cúmplice e passa a assassinar quem quer que se oponha à Light. O problema é que Misa não hesita em matar inocentes, o que desperta uma certa aversão no jovem: sua justiça resume-se a assassinar legitimamente apenas aqueles que ele próprio considera culpados ou que atrapalhem sua empreitada. Tirar a vida de indivíduos que não se enquadrem nessa premissa constitui o autor do ato como um criminoso, e é assim que ele vê a garota: uma criminosa, que logo deverá ser punida. Apesar disso, porém, Light resolve contar com a garota, pois ela possui um poder maior que o dele: tem os olhos do shinigami, um poder que permite matar qualquer pessoa desde que se tenha um rosto, dispensando assim a necessidade de se ter um nome. Para adquirir este poder, o humano deve negociar com um shinigami: o último lhe oferece os olhos, e o primeiro the oferece metade de sua expectativa de vida. $O$ fato de Misa firmar este acordo demonstra quão engajada a personagem é em seguir os ideais de Kira; ela passa a agir inspirada por suas ações, mesmo sem conhecer sua identidade, e após descobrir tratar-se de Light, se coloca ao dispor do jovem.

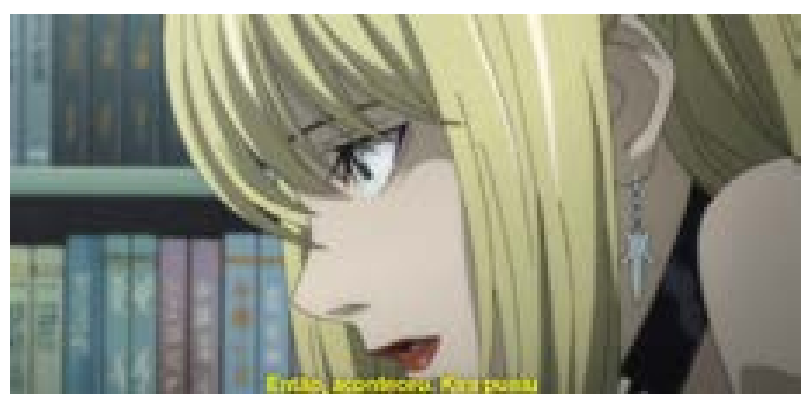

Figura 04: A devoção de Misa

Fonte: Death Note (Desu nôto). Japón: Mad House / D.N. Dream Partners / NTV / Shueisa /Video Audio Project. 2006.

Em determinada cena, Misa confessa à Light que sua admiração pela figura de Kira ocorre após este punir os assassinos de seus próprios pais. Apesar de, em tese, ser uma cena triste - Misa está chorando - as cores utilizadas na imagem são claras. 
A música de fundo não tem qualquer conotação triste, aproximando-se mais de um apelo racional, como se o foco da cena fosse a análise de Light sobre o que fazer com a garota, tanto que a voz chorosa de Misa é acompanhada pelo fundo musical. Percebe-se que Misa é inocente ao acreditar que o estudante seria seu salvador, pois no decorrer da cena torna-se claro que a intenção de Light é aproveitar-se de seus poderes para então puni-la como a assassina que ele entende que ela seja. A garota, assim como parte da opinião pública, não parece perceber que deixando o julgamento de justo e injusto nas mãos de Light, pode ser considerada culpada e condenada a qualquer momento, por qualquer razão que o estudante entenda.

O episódio 30, Justice, é o que mais explicita as justificativas e críticas relativas às ações de Kira. A opinião pública mostra-se bastante favorável ao assassino, pois graças a seus atos a violência diminuiu de forma estrondosa. Uma criança narra os benefícios que Kira fez pela sociedade, sendo sua voz o som de destaque da cena, enquanto uma melodia harmoniosa é tocada ao fundo; nas imagens, são mostrados os cotidianos das pessoas comuns, inclusive com adição sonora de passos, sinais de trânsito e carros, e o terror na voz dos criminosos em revelar seus nomes, pois sabem que Kira irá mata-los. As imagens são apresentadas em preto e branco, de forma a salientar a apatia e o temor da população em relação ao serial killer.

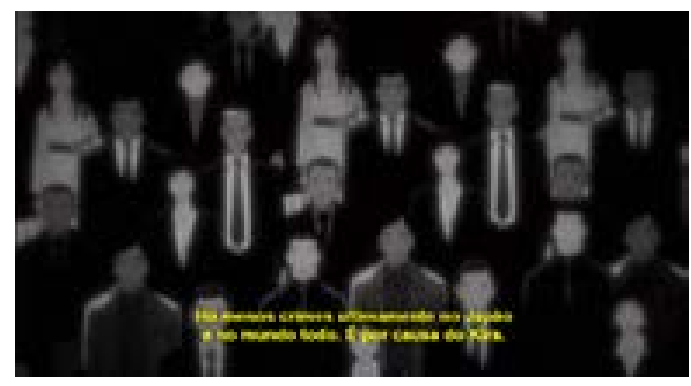

Figura 05: A sociedade apática seguindo sua rotina.

Fonte: Death Note (Desu nôto). Japón: Mad House / D.N. Dream Partners / NTV / Shueisa /Video Audio Project. 2006.

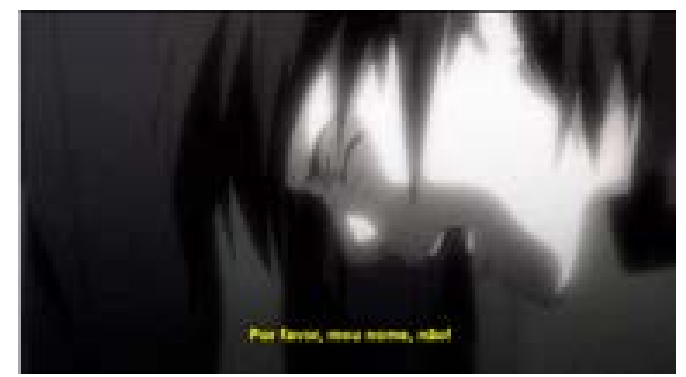

Figura 06: Criminoso desesperado ao saber que seu nome será anunciado.

Fonte: Death Note (Desu nôto). Japón: Mad House / D.N. Dream Partners / NTV / Shueisa /Video Audio Project. 2006.

As cenas também mostram pessoas comuns ameaçando umas às outras de divulgar seus nomes em sites da internet, para que Kira as mate. A música harmoniosa ao fundo soa quase como uma ironia, já que a sociedade vive em torno do medo da justiça de Kira. Um programa sensacionalista passa a venerar a figura de Kira como um Deus, afirmando que contrariá-lo é um crime; o apresentador está sentado em uma cadeira suntuosa, iluminado por uma luz que vem de cima, como se isso significasse que ele, de alguma forma, era um "iluminado". Seu tom de voz é alto e forte, como se fizesse uma propaganda a favor do serial killer. 
Em outro canal, o presidente dos Estados Unidos declara que o país não irá mais caçar o criminoso. Ouvimos os barulhos das câmeras fotográficas, mas não as vemos (caso de imagens negativas); o presidente aparece com uma imagem cansada. Sua voz é de pesar. Assim que seu anúncio é feito, as pessoas se chocam, o que provoca um burburinho do público, trazendo um efeito de síncrese.

Light, que agora atua junto com a polícia japonesa no falso intuito de capturar Kira, assiste a tudo lisonjeado. Por fora, grita de raiva com o posicionamento do presidente americano; mas em seu íntimo, sorri. Essa dualidade entre Kira e Light é bem demonstrada no plano de imagens e sons, já que quando Light assume a identidade de Kira, a imagem passa a ser exibida em vermelho e o seu tom de voz fica calmo, triunfante, como na figura 07.

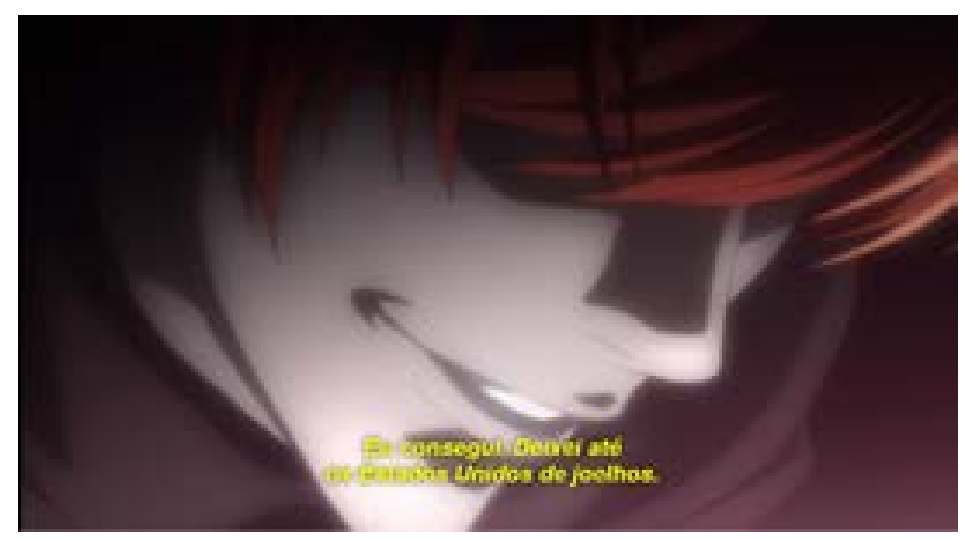

Figura 07: Kira triunfante.

Fonte: Death Note (Desu nôto). Japón: Mad House / D.N. Dream Partners / NTV / Shueisa /Video Audio Project. 2006.

A dualidade entre Light e Kira é bem trabalhada ao longo do anime, especialmente pela sincronização entre som e imagem, como demonstrado anteriormente. No que se refere à justiça de Kira, o anime procura explorar sempre a inocência do público em acreditar que o vilão realmente irá agir em benefício da humanidade; quando críticas são feitas à forma de atuação de Kira, o principal argumento é a de que ele atuaria fora da justiça, mas de qual justiça se fala não é esclarecido. Parecenos que essa ambiguidade é proposital, no intuito de criticar o poder decisivo sobre a vida ou morte das pessoas, independentemente de se tratar de um indivíduo isolado ou da ação do Estado afinal, ao desenrolar da trama, percebe-se que $L$ também não é exatamente um herói, pois não hesita em ignorar direitos humanos e torturar a personagem Misa, que passa a ser uma das principais suspeitas.

Neste sentido, pode-se compreender que a questão da justiça permeia todo o anime, sempre dialogando com as emoções e percepções do espectador, pois afinal de contas, quem dentre os personagens é o real defensor da justiça? A resposta é complexa e plural, justamente porque o conceito de justiça é diversificado e aberto. Nada impede de que a audiência identifique Light como um herói e $L$ como um vilão, ou vice-versa, justamente porque os ideais de cada um são ao mesmo tempo similares e fluidos. Dependendo da situação, matar é uma atitude nobre e justa, seja em nome do Estado, seja em nome de um mundo melhor, independentemente de quem seja a vítima. A única certeza a respeito dos personagens antagonistas é que não se pode tentar impedi-los de realizar suas próprias justiças sem sofrer algum dano. 


\section{Considerações Finais}

Conforme demonstrado, as obras midiáticas procuram articular sons e imagens para reforçar sentidos e significados de seu enredo. Ora utilizadas para conformar, ora para problematizar e levantar questões, não se pode ignorar que sejam importantes instrumentos para se pensar o social.

Assim, procurou-se mostrar como o elemento justiça pode ser representado e problematizado nos textos midiáticos. A partir do anime Death Note, foi possivel verificar que não apenas a imagem, mas também os sons nele presentes auxiliam a compreender o que os personagens entendiam por justiça.

Tendo como foco principal o personagem Light Yagami, foi possível inferir que o jovem acreditava sinceramente estar agindo como um defensor social. A partir de um viés maniqueísta e demasiadamente simplificado para uma sociedade tão complexa, Light elege os bons, os maus e os cúmplices: os primeiros seriam seus protegidos; o segundo, os criminosos que ele deve eliminar e os últimos qualquer um que tente impedir suas ações, independentemente de ter ou não cometido um crime (o crime seria contrariar a vontade do próprio Kira).

Essa ideia de justiça, pautada em proteger os bons e eliminar os maus, também parece guiar as atitudes do antagonista, o detetive $L$. O policial passa a ter como objetivo pessoal a prisão de Kira, para que este fosse condenado à pena de morte. A diferença, neste caso, é que a vontade individual de $L$ encontra amparo do Estado, por meio das instituições jurídicas, já que a pena de morte é uma sanção penal no Japão. Sendo assim, as justiças de Kira e $L$ seriam realmente opostas?

Longe de tentar responder a essa questão, o presente artigo procurou lançar reflexões relativas à ideia de justiça propagada pelo personagem Light Yagami, no intuito de demonstrar como as produções midiáticas japonesas, especificamente os animes, podem ser consideradas importantes fontes para a pesquisa relacionada às artes visuais.

\section{Referências}

CHION, Michel. La audiovisión: Introducción a un análisis conjunto de la imagen y el sonido. Buenos Aires: Paidós 1993.

Death Note (Desu nôto). Japón: Mad House / D.N. Dream Partners / NTV / Shueisa / Video Audio Project. 2006.

JODELET, Denise. Representações sociais: um domínio em expansão. In JODELET, Denise (org). As representações sociais. Rio de Janeiro: UERJ, 2002. p. 17-44.

KELLNER, Douglas. A cultura da mídia - estudos culturais: identidade e política entre o moderno e o pós-moderno. Bauru, SP: Edusc, 2001.

SCHMALTZ NETO, Genis Frederico. Paixões e traços míticos no discurso do animê: uma análise em Death Note. Dissertação. 2013. 128 f. Dissertação (Mestrado em Le- 
tras) - Faculdade de Letras, Universidade Federal de Goiás. Goiânia. 2013.

YAMAMOTO, Lilian. A literatura de cárcere em defesa de um condenado à pena de morte no Japão - Lágrimas da Ignorância, de Norio Nagayama. In: ANAMORPHOSIS - Revista Internacional de Direito e Literatura v. 1, n. 2, julho-dezembro 2015. P. 263179. 